\title{
The influence of the dynamic loading rate on tensile failure properties of metallic materials
}

\author{
H. Couque \\ Nexter Munitions 7 route de Guerry, 18023 Bourges, France
}

\begin{abstract}
The influence of the dynamic loading rate on the tensile failure properties of a series of tungsten alloys and an austenitic stainless steel were investigated by evaluating the flexural strength with unnotched and notched Charpy specimens. These data were generated with a newly developed Hopkinson pressure bar technique. The technique consists in impacting with a striker, at velocities ranging from 25 to $160 \mathrm{~m} / \mathrm{s}$, a round bar specimen placed against two incident Hopkinson pressure bars. Through the recording of the striker velocity before and after impact, failure energy is deduced. At impact velocities greater than $30 \mathrm{~m} / \mathrm{s}$, the results reveal a surprising increase of the Charpy energy with the increase of the impact velocity for both types of metallic materials. The results have been interpreted through numerical simulations of the Charpy test, the dependence of the material flow stress with the strain rate, and observations of the failure mechanisms. It was found that at impact velocities greater than $30 \mathrm{~m} / \mathrm{s}$, tangential strain rates exceed $3000 \mathrm{~s}^{-1}$ at the failure initiation site of the Charpy specimen. These strain rates are within the strain rate regime where strengthening occurred due to the viscous behaviour of the dislocations. Data generated with moderate stress concentration using notched round bar Charpy specimens indicate that the strengthening occurring at high strain rates continues to pilot the tensile failure processes.
\end{abstract}

\section{Introduction}

Data on the influence of strain rate on the tensile strength of metallic materials generated with conventional tensile specimens are limited to strain rates of $2000 \mathrm{~s}^{-1}[1]$. These data are usually generated with the tensile set-up of the Kolsky-Hopkinson pressure bars technique. At these strain rates, metallic materials deform plastically through the thermal activation of the dislocations and reveal little increase of the tensile strength. When higher strain rates are applied, no much information are available. This is principally due to the loading device of the tensile KolskyHopkison pressure bars technique, which limits the strain rate to about $2000 \mathrm{~s}^{-1}$.

It is necessary to use another mean to access the tensile properties in the $10^{3}-10^{4} \mathrm{~s}^{-1}$ strain rate regime. Recently, a newly Hopkinson pressure bar technique has been developed by the author to access these tensile properties through the analysis of flexural strength data generated at different loading rates involving a Charpy like specimen [2]. In this work, extremely high increase of the tensile strength was revealed when strain rates reach the regime where the viscous drag behaviour of the dislocations prevailed [2].

The present investigation reports on extended data generated with this technique for a series of tungsten alloys in the as-sintered and swaged conditions, along with a highly ductile austenitic stainless steel A304L. These metallic materials cover a large range in quasi-static yield stress from 500 to $1700 \mathrm{MPa}$ and ductility from 6 to $50 \%$, see Table 1.

Charpy data of the metallic materials were generated with notched and unnotched round bar like Charpy specimen impacted at velocities ranging from 25 to $160 \mathrm{~m} / \mathrm{s}$. To generate such impact velocities, a gas gun is used to propel a striker impacting the Charpy specimen placed against two Hopkinson pressure bars. With the use of this newly
Table 1. Mechanical properties of the conventional tungsten alloys and the stainless steel.

\begin{tabular}{|l|l|l|l|l|}
\hline Material & $\begin{array}{l}\text { Yield } \\
\text { stress } \\
(\mathrm{MPa})\end{array}$ & $\begin{array}{l}\mathrm{E} \\
(\%)\end{array}$ & $\begin{array}{l}\text { Unnotched } \\
\text { Charpy energy } \\
\left(\mathrm{Joules} / \mathrm{cm}^{2}\right)\end{array}$ & Name \\
\hline Swaged 91\%W & 1720 & 6 & 90 & $91 \mathrm{~W}$ \\
\hline Swaged 60\%W & 2000 & 8 & 400 & $60 \mathrm{~W}$ \\
\hline As sintered 91\%W & 768 & 24 & 325 & $91 \mathrm{~W}-\mathrm{AS}$ \\
\hline A304L & 506 & 50 & $120 *$ & A7 \\
\hline
\end{tabular}

* Notched Charpy energy.

Hopkinson pressure bar technique, the study of the effect of the impact velocity on the flexural failure strength has been made possible [2].

\section{Materials}

The materials tested consist of as-sintered and swaged tungsten alloys made by Cime Bocuze and an austenitic stainless steel A304L made by Thyssen. Their mechanical properties are provided in Table 1. The tungsten alloys belong to the tungsten, nickel and cobalt system with 60 and $91 \%$ tungsten content in mass. The materials were elaborated in bar 10 to $11 \mathrm{~mm}$ in diameter from which tensile, compression and round Charpy specimens were machined.

The tungsten alloys with $91 \%$ of tungsten exhibit a contiguous network of nearly pure bcc tungsten grains, known as the alpha phase $(\alpha)$, embedded within a ductile fcc matrix rich in nickel known as the gamma phase $(\gamma)$, see Figure 1. The gamma phase contains other elements such as cobalt and tungsten. The tungsten grains of the as sintered tungsten alloy are $19 \mu \mathrm{m}$ in size. The swaged 


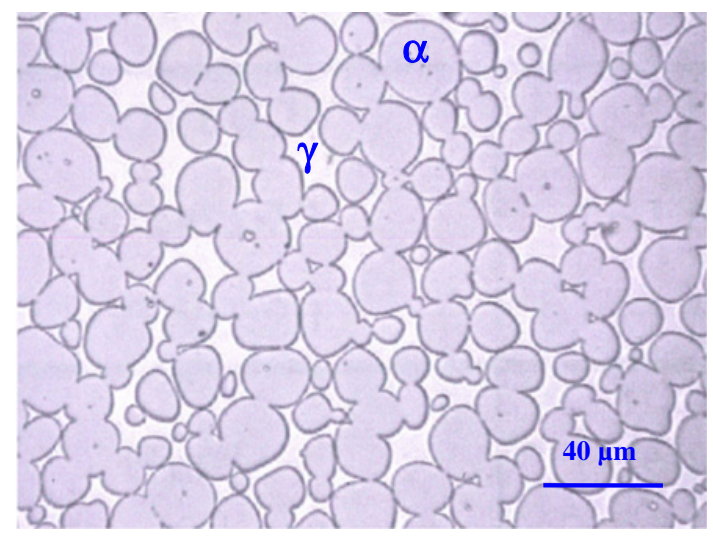

Fig. 1. Micrograph of the swaged $91 \% \mathrm{~W}$ alloy $(91 \mathrm{~W})$ revealing bcc tungsten grains (dark $-\alpha$ phase) embedded in a fcc matrix (clear - $\gamma$ phase)

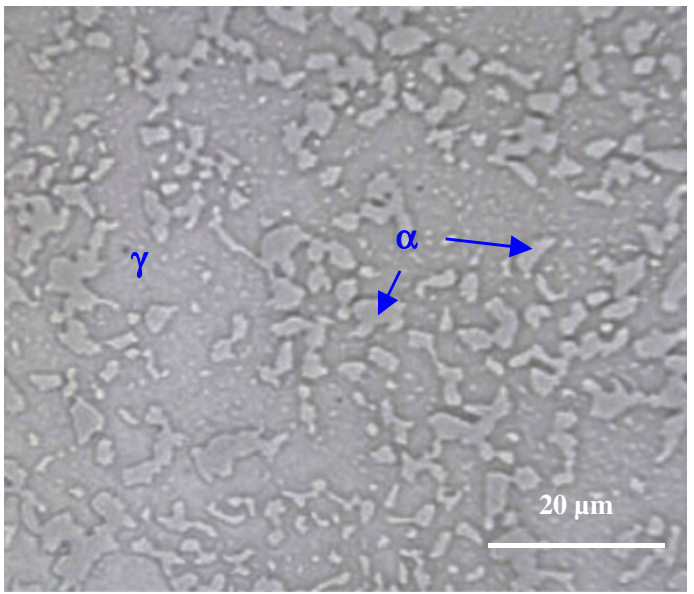

Fig. 2. Micrograph of the $60 \% \mathrm{~W}$ alloy revealing a fcc matrix ( $\gamma$ phase) with isolated bcc tungsten grains ( $\alpha$ phase).

alloy exhibits a texture characterized by elongated tungsten grains, $23 \mu \mathrm{m}$ in length, along the bar axis, and round tungsten grains, $17 \mu \mathrm{m}$ in size, in the direction normal to the bar axis. For the tungsten alloy with $60 \%$ of tungsten, a continuous gamma phase is obtained with isolated pure bcc tungsten grains of about $5 \mu \mathrm{m}$ in size, see Figure 2 . The observations in Figures 1 and 2 were made in the direction normal to the bar axis.

The stainless steel is of the type $304 \mathrm{~L}$ containing $10 \%$ of nickel and $18 \%$ of chromium. The microstructure is typical a fcc material with a high contain of twins, see Figure 3. The average grain size is $100 \mu \mathrm{m}$.

\section{Experimental procedure}

The round bar Charpy experiment consists of the dynamic loading of a three point bend specimen $60 \mathrm{~mm}$ in length, see Figure 4. Specimens were either 5.6, 8.4 or $10.8 \mathrm{~mm}$ in diameter. Notched specimens were also used with a circular notch $2 \mathrm{~mm}$ in depth having a notch radius of $250 \mu \mathrm{m}$.

The specimen is impacted by a striker bar $10 \mathrm{~mm}$ in diameter and $84 \mathrm{~mm}$ in length at velocity ranging from 25

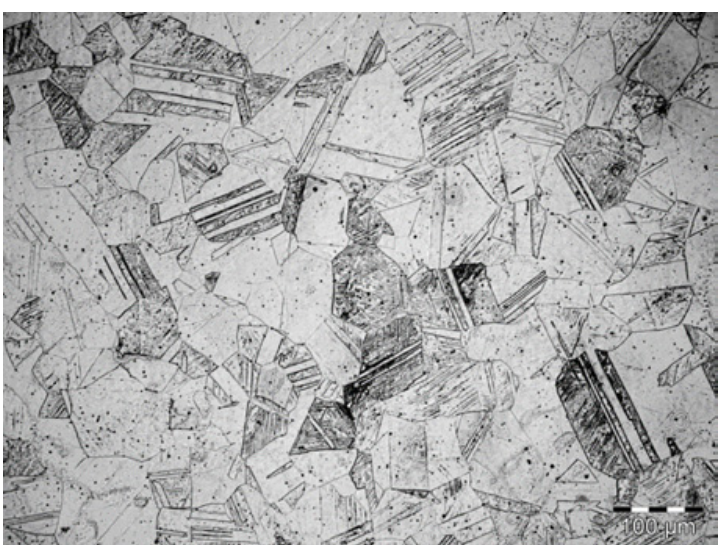

Fig. 3. Micrograph of the austenitic steel A304L revealing grains with a high density of twins.

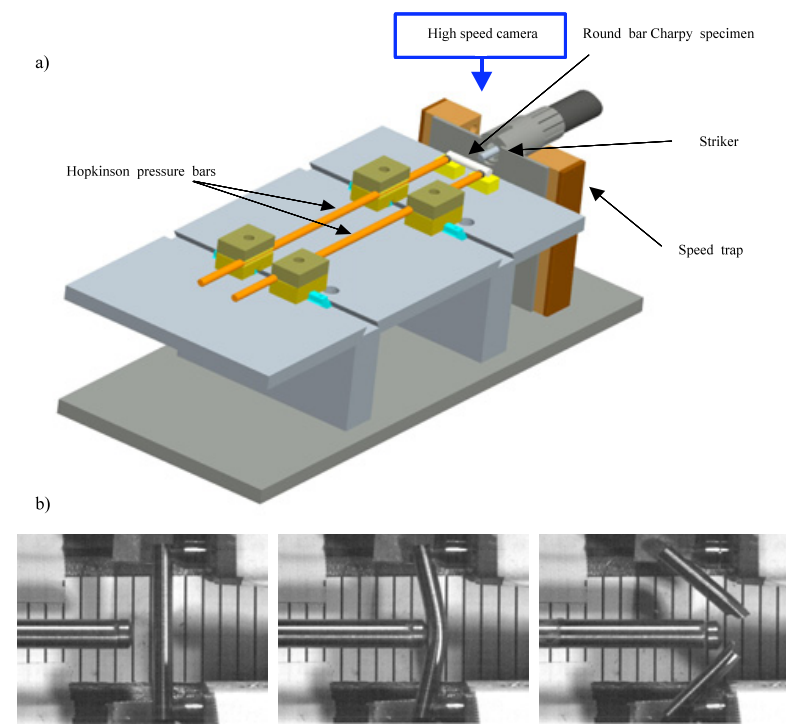

Fig. 4. Round bar Charpy experiment: (a) setup, (b) high speed camera observations for a striker launched at $30 \mathrm{~m} / \mathrm{s}$ against a $91 \mathrm{~W}$ specimen $5.6 \mathrm{~mm}$ in diameter.

to $160 \mathrm{~m} / \mathrm{s}$. The specimen is placed against two Hopkinson pressure bars $10 \mathrm{~mm}$ in diameter as to record the contact loads. Both striker and Hopkinson pressure bars are made of swaged $91 \% \mathrm{~W}$ alloy. The striker guided by a Teflon sabot is sent using a gas gun. The impact velocity is first monitored with a two laser beams device placed $40 \mathrm{~mm}$ before impact.

A specific setup has been developed, in one hand to arrest the Teflon sabot, and in another hand to guide the striker up to impact through continuous sliding of the striker in the Teflon sabot. The velocity at impact and after impact of the striker are deduced from high speed camera observations.

The difference between the kinetic energy of the striker before and after impact provides the energy consumed by the round Charpy specimen. The kinetic energy of the broken round Charpy specimen after impact was found to be less than $1 \%$ of the total energy absorbed by the specimen. Consequently, the round bar Charpy energy, K, 
was estimated by:

$$
\mathrm{K}=0.5 \mathrm{~m}_{\mathrm{s}}\left(\mathrm{Vi}^{2}-\mathrm{Vr}^{2}\right) / \mathrm{S},
$$

with $\mathrm{m}_{\mathrm{s}}$ is the mass of the striker, $\mathrm{Vi}$ is the velocity of the striker at impact, $\mathrm{Vr}$ is the residual velocity of the striker after impact, and $\mathrm{S}$ the cross section area of the round bar Charpy specimen.

\section{Mechanical results}

The round bar Charpy energy as a function of the striker impact velocity is reported for the tungsten alloys in Figures 5(a) and 5(b). The data generated from conventional unnotched Charpy $5 \times 5 \mathrm{~mm}^{2}$ tests by the elaborator are also reported with an impact velocity of $5 \mathrm{~m} / \mathrm{s}$. Up to $50 \mathrm{~m} / \mathrm{s}$, the failure energy is about constant. A complete different response is obtained when higher impact velocities are applied.

A surprising increase of the failure energy was observed for the swaged $91 \mathrm{~W}$ alloy $(91 \mathrm{~W})$, reaching up to six times the conventional Charpy energy at an impact velocity of $110 \mathrm{~m} / \mathrm{s}$. At the same impact velocity, the as sintered tungsten alloy (91 W-AS) and the $60 \mathrm{~W}$ tungsten alloy reveal a more drastic increase, reaching Charpy energy as high as 1000 Joules $/ \mathrm{cm}^{2}$.

For the stainless steel A7 no failures were generated with the unnotched Charpy specimens. In consequence, notched round Charpy specimens with a $250 \mu \mathrm{m}$ circular notch were machined. Notch Charpy specimens $5 \times 5 \mathrm{~mm}^{2}$ were also tested to compare with conventional Charpy data generated by the elaborator. With this Charpy specimen configuration, failures were generated. A similar trend as for the tungsten alloys was observed with a failure energy reaching up to nine times the conventional notched Charpy energy, see Figure 5(c).

The increase of the Charpy energy with the impact velocity was analyzed through several investigations. First, an investigation was conducted to precise the mechanical loading conditions through simplified numerical simulations of the round bar Charpy experiment. Second, an investigation was realized to establish the strain rate dependence of the flow stress at strain rates reached with these Charpy specimens. Finally, the Charpy failure energy was interpreted through the identifications of the failure mechanisms.

Because swaged bar tungsten alloys exhibit a microstructure and residual stresses dependant of the radius, these investigations were limited to data generated with $5.6 \mathrm{~mm}$ diameter Charpy specimens $\left(25 \mathrm{~mm}^{2}\right.$ in area) as to relate with conventional $5 \times 5 \mathrm{~mm}^{2}$ square Charpy specimen data.

Numerical simulations of the Charpy experiment were conducted with the hydrocode Autodyn to estimate the tangential strain rate reached at the initiation failure site of the three point bend specimen $5.6 \mathrm{~mm}$ in diameter. A simplified model was generated using plates for the striker, specimen and Hopkinon pressure bars with a plate thickness equal to the associated diameter providing an equivalent tangential strain rate. Figure 6 describes the correspondence between the tangential strain rate and the a)

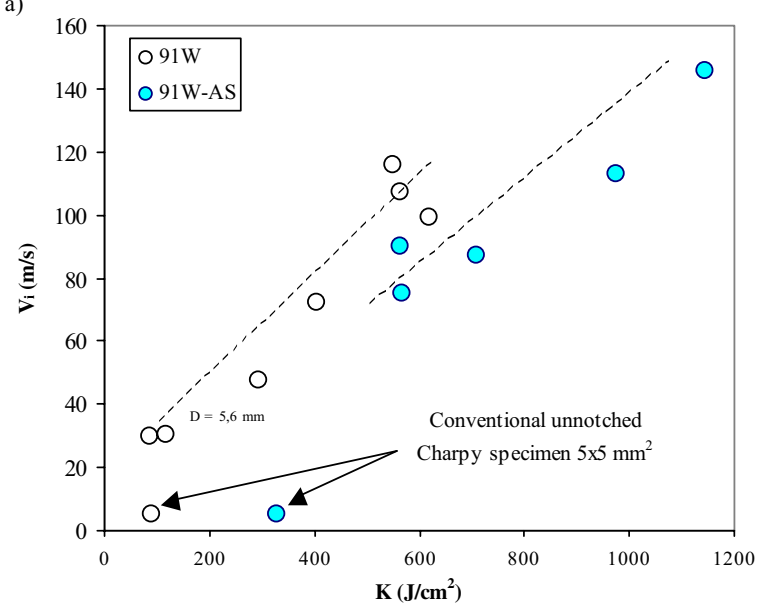

b)

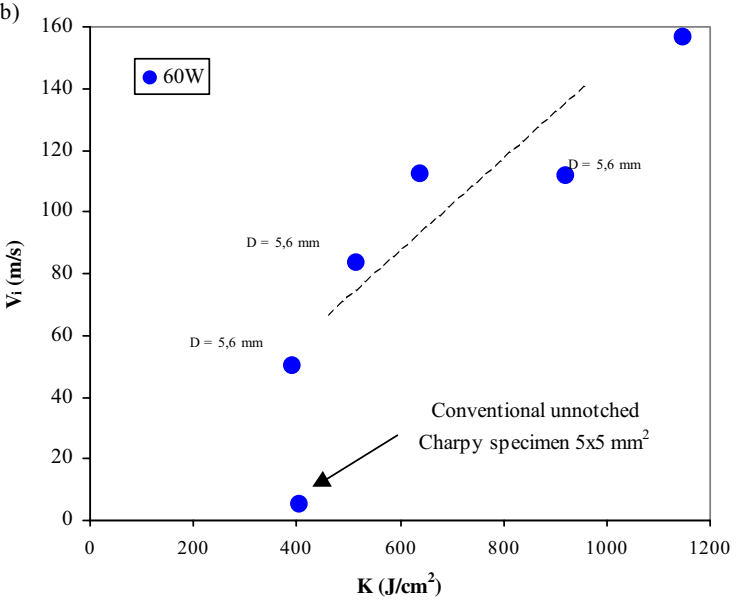

c)

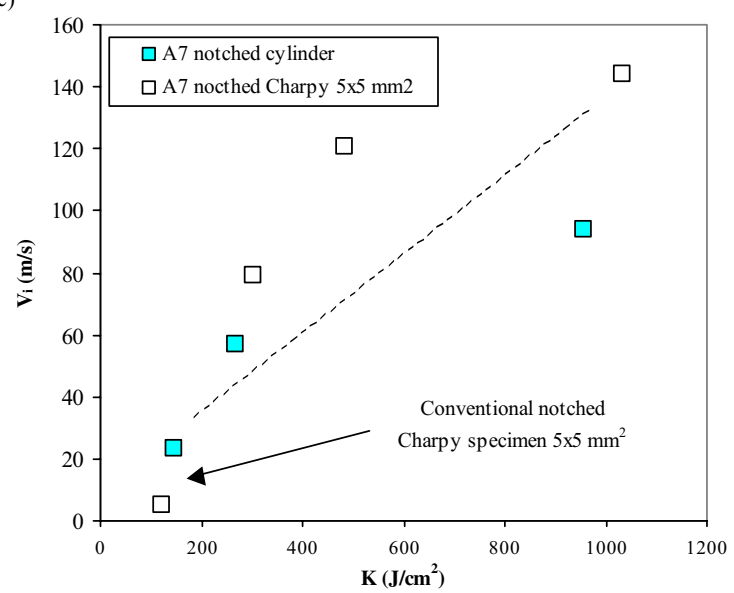

Fig. 5. Impact velocity of the striker function of the Charpy energy for (a) the $91 \mathrm{~W}$ alloys, (b) the $60 \mathrm{~W}$ alloy and (c) the austenitic steel A7.

impact velocity. When considering an impact velocity of $5 \mathrm{~m} / \mathrm{s}$, typically applied to conventional $5 \times 5 \mathrm{~mm}^{2}$ Charpy specimens, the tangential strain rate is about $500 \mathrm{~s}^{-1}$. Such result is in agreement with strain rates measured with conventional Charpy specimens [3]. When considering Charpy specimens impacted at a velocity greater than $30 \mathrm{~m} / \mathrm{s}$, the tangential strain rate exceeds $3000 \mathrm{~s}^{-1}$. As expected due to inertia effects, lower strain rates are reached 


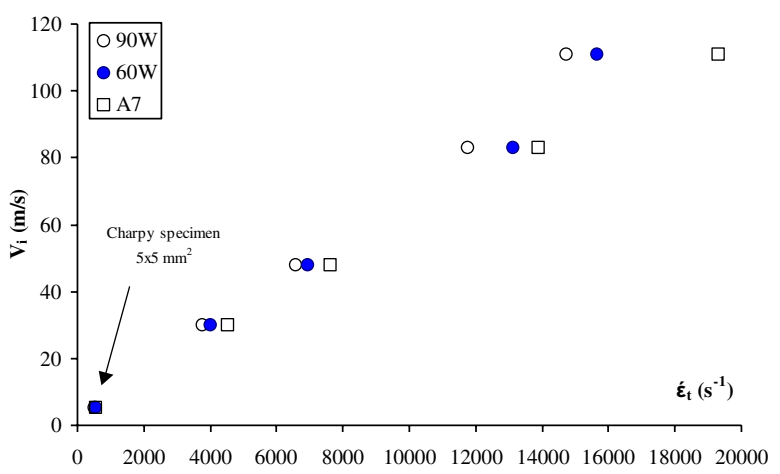

Fig. 6. Impact velocity of the striker function of the equivalent tangential strain rate at the failure site of the round bar Charpy specimen of diameter $5.6 \mathrm{~mm}$ for the $\mathrm{W}$ alloys and the steel.

with the tungsten alloys when compared to the lighter metal, A7 steel.

High strain rate compression tests were performed with a conventional testing machine Kolsky-Hopkinson pressure bars, and a direct impact Hopkinson pressure bar as to identify the thermally activated and viscous regimes. The tests were conducted with specimens $9 \mathrm{~mm}$ in diameter and $5 \mathrm{~mm}$ in height, following a procedure conducted by the author on nickel [4]. Figure 7 shows the flow stresses at a plastic deformation of 0.01 as a function of strain rate for the $\mathrm{W}$ alloys and the steel. The figure reveals, for the tungsten alloys and the austenitic steel, a transition from thermally activated to viscous drag behaviour of the dislocations at a strain rate of about $1000 \mathrm{~s}^{-1}$.

The loading conditions and strain rate sensitivities now identified, the increase of the Charpy energy with impact velocity can be examined by analysing the fractographs of the Charpy specimens.

\section{Fractographs results}

Figure 8 shows fractographs of the $91 \mathrm{~W}$ specimens tested at impact velocity of 30 and $48 \mathrm{~m} / \mathrm{s}$. Both specimens exhibit a similar pattern, with a network of cleaved tungsten particles (W) surrounded by dimples corresponding to the void coalescence and growth of the matrix phase $(\mathrm{M})$. Also identified, somehow in a limited quantity, are the tungsten/tungsten interface failures (W/W).

These failure mechanisms are similar to those observed at $5 \mathrm{~m} / \mathrm{s}$ with conventional unnotched Charpy specimens as well as with quasi-static and dynamic fracture toughness $\mathrm{K}_{\mathrm{Ic}}$ and $\mathrm{K}_{\mathrm{Id}}$ specimens [5], therefore not providing an explanation to the increase of the Charpy energy with the increase of the impact velocity. A similar trend was revealed with the as sintered alloy, $91 \mathrm{~W}-\mathrm{AS}$, as shown in Figure 9.

For the as sintered and swaged $91 \mathrm{~W}$ alloys, the increase of Charpy energy with the impact velocity seems to come from two strengthening characteristics: - First, tungsten particles are driving the strength of the tungsten alloys. The high yield strength of tungsten alloys, 760$2000 \mathrm{MPa}$, originates from the plastic deformation of the tungsten particles, since the swaged matrix rich in nickel
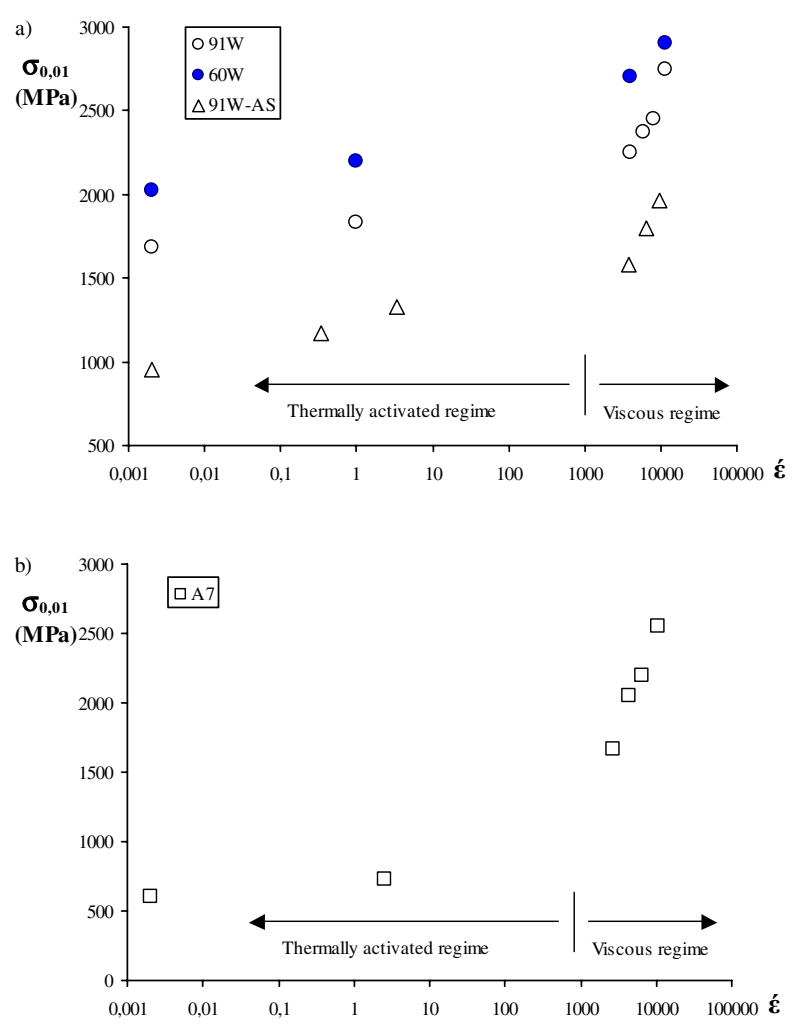

Fig. 7. Flow stress at a plastic strain of 0.01 versus strain rate for a) $60 \mathrm{~W}$ and $91 \mathrm{~W}$ alloys, and b) the austenitic steel A7.

a) $30 \mathrm{~m} / \mathrm{s}$

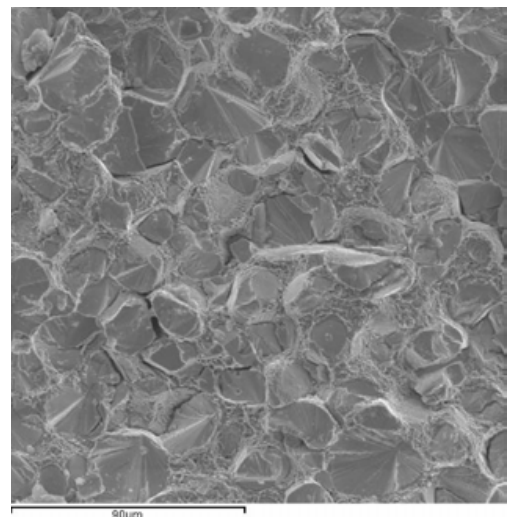

b) $48 \mathrm{~m} / \mathrm{s}$

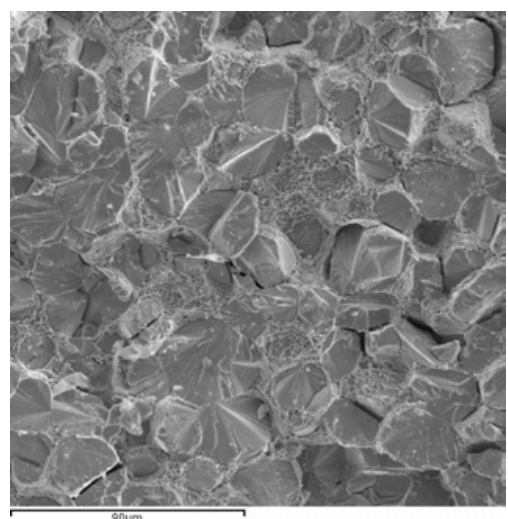

Fig. 8. Fractographs of the swaged $91 \mathrm{~W}$ specimens tested at an impact velocity of 30 (a) and $48 \mathrm{~m} / \mathrm{s}$ (b). 
a) $75 \mathrm{~m} / \mathrm{s}$

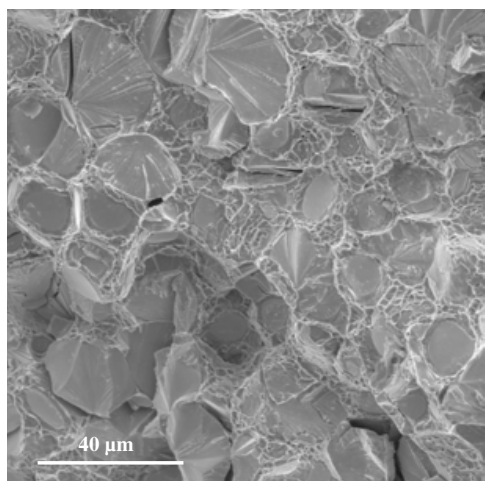

b) $146 \mathrm{~m} / \mathrm{s}$

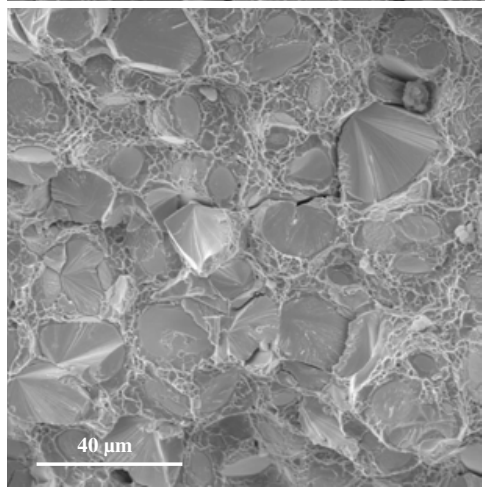

Fig. 9. Fractographs of the as sintered $91 \mathrm{~W}$ specimens tested at an impact velocity of 75 (a) and $146 \mathrm{~m} / \mathrm{s}$ (b).

is known to reach a much lower yield stress of the order of $700 \mathrm{MPa}$ [6]. Polycrystalline pure tungsten is known to be brittle because of the weak grain boundaries (W/W). In the case of tungsten alloys, few W/W interfaces are presents and their failures do not favour crack propagation [2], therefore allowing the strengthening of these alloys through the hardening of the tungsten particles; - Second, the strength increases when strain rates reach the viscous regime. Impact tests starting at a velocity over $30 \mathrm{~m} / \mathrm{s}$ provide loading conditions within the viscous regime where strengthening of both bcc and fcc phases occurred. For example, at an impact velocity of $48 \mathrm{~m} / \mathrm{s}$, the strain rate exceeds $6500 \mathrm{~s}^{-1}$, recall Figure 6, which is within the viscous regime as shown in Figure 7.

With the increase of the impact velocity from 30 to $48 \mathrm{~m} / \mathrm{s}$ for the $91 \mathrm{~W}$, the two strengthening characteristics result in a delay of the cleavage failures of the tungsten particles explaining the increase of the Charpy energy from 85 to 290 Joules $/ \mathrm{cm}^{2}$.

When considering the $60 \mathrm{~W}$ alloy, the failure process is quite different with the presence of shear lips signature of a highly ductile failure occurring under a plane stress state of stress [2]. The fact that plane stress failure occurred reveals that large plastic deformations prevailed through the entire tensile loading region of the round bar Charpy specimen. With the increase of the impact velocity, the amount of circumferential shear lips increase of the exterior region submits to tensile loading. This is probably due the late plastic deformation of the plane strain zone of the tensile specimen originating from the strengthening occurring in the viscous regime.

The high failure energy of the $60 \mathrm{~W}$ is due, in one hand, to the large amount of failed matrix (M) witness of high a) $83 \mathrm{~m} / \mathrm{s}$

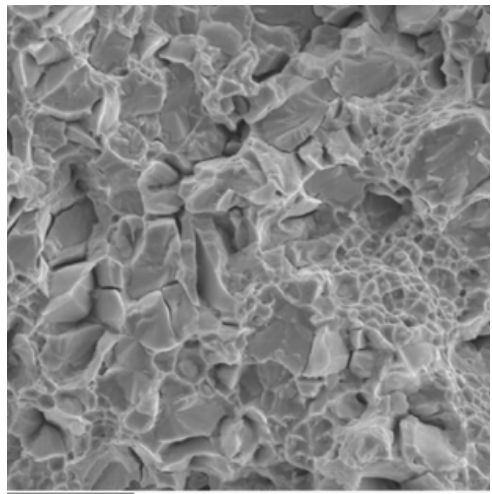

b) $111 \mathrm{~m} / \mathrm{s}$

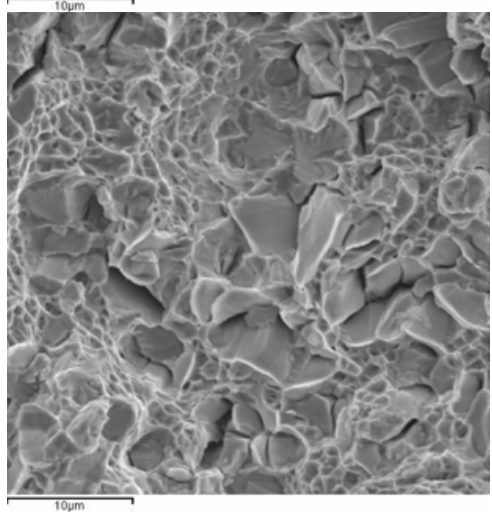

Fig. 10. Fractographs of the as sintered $60 \mathrm{~W}$ specimens tested at an impact velocity of 83 (a) and $111 \mathrm{~m} / \mathrm{s}$ (b).

intrinsic ductility, and in another hand, to the strengthening of both tungsten particles and matrix occurring at these impact velocities, recall Figures 6 and 7. The fact that tungsten/matrix interface failures are observed is also a sign that high stresses are reached.

For the austenitic steel, a homogeneous network of voids 5 to $10 \mu \mathrm{m}$ has been generated, as shown in Figure 11. It appears that the critical strain for void nucleation is independent of the strain rate. Such results go along with the quasi-static and dynamic fracture toughness investigation of a $0.20 \% \mathrm{C}$ steel revealing that ductile toughness, $\mathrm{K}_{\mathrm{Ic,d}}$, scales with the strength of the steel [7]. As for the tungsten alloys, the strengthening occurring in the viscous regime appears to be the origin of the increase of the Charpy energy of the steel with the impact velocity.

For the A7 steel, the tensile strengthening is occurring in despite of the small stress concentration generated with the use of $250 \mu \mathrm{m}$ circular notch. Such tensile strengthening with the use of notch specimens has been confirmed with a $91 \%$ tungsten alloy $1540 \mathrm{MPa}$ in yield stress. Notch of 125,250 , and $500 \mu \mathrm{m}$ were used at a impact velocity of $110 \mathrm{~m} / \mathrm{s}$ with specimens $10.8 \mathrm{~mm}$ in exterior diameter [2]. At this impact velocity, the tangential strain rate is about $6000 \mathrm{~s}^{-1}$, based on numerical simulations with the $10.8 \mathrm{~mm}$ in diameter unnotched Charpy specimen, which is well within the viscous regime. The notch, down to a root radius of $125 \mu \mathrm{m}$, does not reduce dramatically the Charpy energy as it has been usually measured with conventional Charpy specimens [2]. When considering dynamic fracture toughness data $[5,8,9]$, the stress concentration of sharp cracks is high enough to overcome the 
a) $24 \mathrm{~m} / \mathrm{s}$

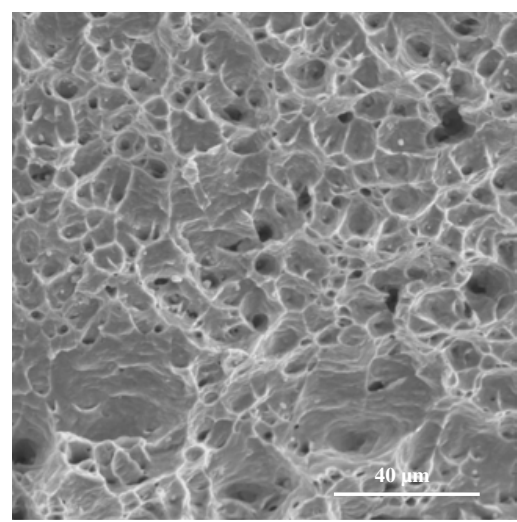

b) $94 \mathrm{~m} / \mathrm{s}$

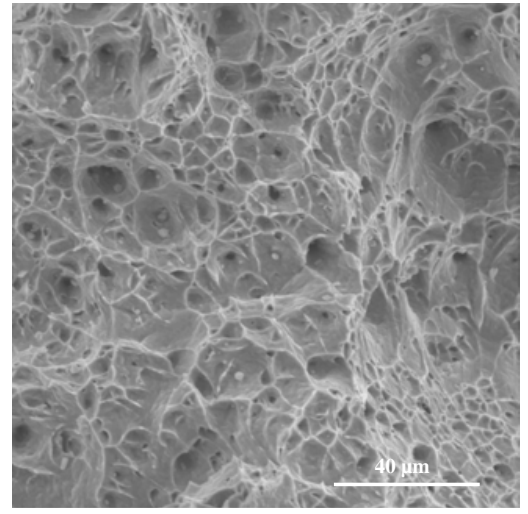

c) $142 \mathrm{~m} / \mathrm{s}$

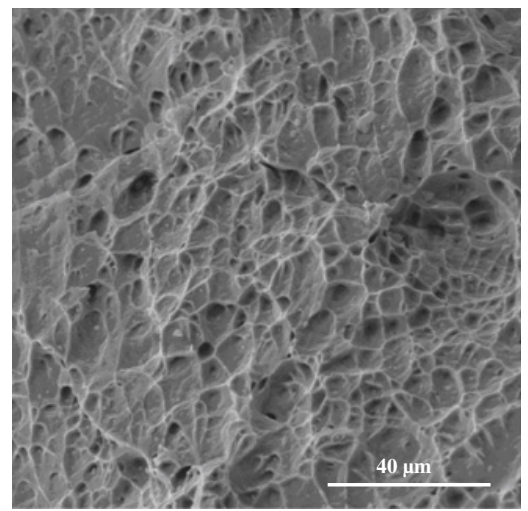

Fig. 11. Fractographs of the $A 7$ notched specimens tested at an impact velocity of 24 (a), $94 \mathrm{~m} / \mathrm{s}$ (b) and $142 \mathrm{~m} / \mathrm{s}$ (c).

tungsten particles strengthening, resulting for $91 \mathrm{~W}$ type of alloys in low dynamic toughness $\mathrm{K}_{\mathrm{Id}}, 19$ to $35 \mathrm{MPa}$ $\sqrt{\mathrm{m}}$, at a loading rate of $10^{6} \mathrm{MPa} \sqrt{ } \mathrm{m} \mathrm{s}^{-1}$. Analytical and numerical investigations are required to confirm that stress singularities of the dynamically loaded notched Charpy specimens are low enough to delay the failure of the tungsten particles.

\section{Conclusions}

New insights on the influence of loading rate in the tensile strength of a series of tungsten alloys and an austenitic have been generated with round bar Charpy type specimen loaded with a newly developed Hopkinson bars technique. The results reveal a surprisingly increase of the Charpy energy with the increase of the impact velocity from 25 to $160 \mathrm{~m} / \mathrm{s}$. This increase was interpreted through the strengthening occurring at high strain rates when the viscous behaviour of the dislocations prevailed. For the tungsten alloys, such strengthening appears to delay significantly the plasticity driven cleavage failure of the tungsten particles, confirming that these particles play a major role in generating high strength tungsten alloys. It was also found that this strengthening behaviour pilots the failure process when moderate stress concentrations are presents, like in notched Charpy specimens.

\section{Acknowledgements}

The author thanks Dr. Bruno Salesse and M. Fabien Hemeret from Nexter Systems for generating the fractographs, and MM. Pascal Vanneau, Didier Gaspard and Richard Roy from Nexter Munitions for conducting the experiments. This research was in part sponsored by the Direction Générale de l'Armement.

\section{References}

1. T. Nicholas, Exp. Mech., 21, 177-188 (1981)

2. H. Couque, Tungsten and Tungsten Alloys - Recent Advances TMS Conf., Ed. A. Crownson and E. Chen, 6, 24-35 (2011)

3. R. Piques and A. Pineau, Eng. Fracture Mechanics, 72, 413 (2005)

4. H. Couque, R. Boulanger and F. Bornet, J. Phys. IV France, 134, 87 (2006)

5. H.Couque, J. Lankford and A. Bose, J. Phys. III, 2225 (1992)

6. H. Couque, A. Molinari, B. Salesse and G. Nicolas, Tungsten, Refractory and Hard Metals VI Conf., Ed. A. Bose et R. Dowding, 385 (2006)

7. H. Couque, R. Asaro, J. Duffy et S. Lee, Metall. Trans. A, 19A, 2179 (1988)

8. S. Bless and R. Chau, Shock Compression of Condensed Matter Conf., Ed. M. Furnish et al., 603 (2005)

9. D. Rittel, R. Levin and A. Dorogoy, Metall. Trans. A, 35A, 3787 (2004) 